\title{
Afrique : villes et violences
}

Laurent FOURCHARD et Isaac Olawale ALBERT (éds), Sécurité, crime et ségrégation dans les villes d'Afrique de l'Ouest du XIX ${ }^{\mathrm{e}}$ siècle à nos jours, Paris, Karthala, et Ibadan, Institut français de recherche en Afrique (IFRA), 2003, $451 \mathrm{p}$.

Jean-Fabien Steck

\section{(QpenEdition}

\section{Journals}

Édition électronique

URL : http://journals.openedition.org/transcontinentales/1414

DOI : $10.4000 /$ transcontinentales. 1414

ISBN : 978-2-8218-1410-3

ISSN : 1775-397X

\section{Éditeur}

Editions de la maison des sciences de l'homme

\section{Édition imprimée}

Date de publication : 31 décembre 2005

Pagination : 147-149

ISBN : 2200-92168-3

ISSN : 1950-1684

\section{Référence électronique}

Jean-Fabien Steck, «Afrique : villes et violences », Transcontinentales [En ligne], 1 | 2005, document 13, mis en ligne le, consulté le 25 septembre 2020. URL : http://journals.openedition.org/ transcontinentales/1414; DOI : https://doi.org/10.4000/transcontinentales.1414

Ce document a été généré automatiquement le 25 septembre 2020

Tous droits réservés 


\section{Afrique : villes et violences}

Laurent FOURCHARD et Isaac Olawale ALBERT (éds), Sécurité, crime et ségrégation dans les villes d'Afrique de l'Ouest du XIX ${ }^{\mathrm{e}}$ siècle à nos jours, Paris, Karthala, et Ibadan, Institut français de recherche en Afrique (IFRA), 2003, 451 p.

\section{Jean-Fabien Steck}

\section{RÉFÉRENCE}

Laurent FOURCHARD et Isaac Olawale ALBERT (éds), Sécurité, crime et ségrégation dans les villes d'Afrique de l'Ouest du XIX ${ }^{\mathrm{e}}$ siècle à nos jours, Paris, Karthala, et Ibadan, Institut français de recherche en Afrique (IFRA), 2003, $451 \mathrm{p}$.

1 La question de la sécurité urbaine est aujourd'hui en Afrique une question majeure qui attire l'attention d'un nombre croissant d'observateurs : les journalistes y consacrent de longs articles, les investisseurs s'y intéressent de près, les politiques en parlent... et les chercheurs se sont appropriés ce nouveau thème de recherche. L'ouvrage dont il est question ici est une sélection de 25 articles (en français ou en anglais) présentés lors d'un colloque qui s'est tenu fin 2001 à l'université d'Ibadan (Nigeria) sur l'initiative de l'Institut français de recherche en afrique (IFRA) en collaboration avec l'Institute of African Studies et le Centre for Urban and Regional Planning. Au côté d'auteurs français et nigérians, des intervenants sont aussi venus du Sénégal, du Togo, de la Gambie, du Kenya.

2 En introduction, L. Fourchard souligne la nécessité d'une approche historique comparatiste, tandis que I. O. Albert revient sur le concept de "sécurité », en insistant sur ses dimensions sociales et en interrogeant les liens entre sécurité, crime et développement. Cette double entrée, très stimulante, est essentielle à la compréhension des enjeux de l'ouvrage.

3 La première partie est consacrée à une présentation historique des relations entre crime et politiques sécuritaires en Europe et en Afrique de l'Ouest. On constate combien, tant dans les métropoles (France et Grande-Bretagne) que dans leurs colonies, 
ces questions renvoient toujours à la stigmatisation d'un groupe bien particulier, à sa localisation dans la ville et à sa visibilité dans la rue (L. Fourchard). À suivre O. Goerg, une certaine continuité apparaît même dans la gestion de la sécurité urbaine: les politiques urbaines coloniales ségrégationnistes s'appuyaient en effet sur des arguments sécuritaires et sanitaires qui ne sont pas si différents de ceux que l'on pouvait rencontrer en Europe dans la seconde moitié du XIXe siècle.

Ces pratiques urbanistiques, passées ou présentes, répondent aussi aux représentations que l'on se fait des questions sécuritaires. La deuxième partie de l'ouvrage les explore, qu'il s'agisse de la représentation souvent très négative de la ville dans la littérature africaine (D. Coussy), de la mauvaise réputation des bandes de jeunes à Lagos dans un contexte de violence politique peu propice à la promotion de discours citoyens (A. Momoh), ou des fantasmes que suscite une ville comme Johannesburg (P. Guillaume). Manque peut-être ici une étude sur les représentations criminogènes qu'engendre encore aujourd'hui l'informel, étudié sous un angle historique colonial par L. Fourchard. Ce secteur occupe la majeure partie de la population active urbaine et il est présenté par certains auteurs comme un des moyens d'assurer l'intégration économique de toute une population «à risques ».

5 La question de la ségrégation comme garantie sécuritaire apparaît essentielle. Fondée à la fois sur la distance entre quartiers et sur l'homogénéité interne de chacun des fragments urbains, elle est au cœur de la troisième partie de l'ouvrage. Après un cadrage général consacré aux relations entre Européens et Africains dans les villes nigérianes (A. Olukoju), où l'auteur montre, entre autres, combien la politique sécuritaire et ségrégationniste coloniale pouvait parfois poser des problèmes d'application auprès des missionnaires et des maisons de commerce, quatre monographies historiques (au Cameroun et au Nigeria) permettent de bien saisir les différents enjeux sécuritaires des politiques ségrégationnistes, notamment entre populations africaines autochtones et allochtones, de plus en plus nettement distinguées et séparées. Ces politiques ségrégationnistes ne manifestent pas seulement une gestion de la sécurité urbaine : elles répondent d'abord à des impératifs politiques. L'ordre colonial y a trouvé son compte, ainsi que les régimes post-coloniaux et actuels qui ont souvent utilisé les mêmes recettes, pour assurer la défense de l'ordre établi et, dans certains cas, de leurs pouvoirs autoritaires.

6 La persistance de la criminalité dans le temps, voire son renforcement dans un contexte de croissance urbaine et de crises (économiques, sociales et politiques), pose la question de la capacité des États à répondre à ce défi. Des États très souvent discrédités : les forces de l'ordre, en nombre insuffisant pour leur tâche, ont en fait un rôle politique ; elles sont minées par la corruption et bien souvent sous-équipées (d'autant que la multiplication des conflits alimente les criminels en armes de guerre). On assiste dès lors à une véritable "privatisation de la sécurité ", objet de la quatrième et dernière partie de l'ouvrage. Celle-ci passe par un recours aux autorités traditionnelles (T. Agbola et O. Sobanjo), par un repli communautaire où l'origine géographique - même lointaine dans l'espace et dans le temps - peut apparaître comme un « rempart contre les formes d'insécurité identitaire et économique » (J.-L. Martineau), voire par une mobilisation des réseaux évangéliques et pentecôtistes (C. Mayrage). Apparaissent ainsi de véritables milices qui représentent davantage un danger supplémentaire qu'une solution sécuritaire durable et équitable (M.-A. de Montclos). Il y a des motifs d'inquiétude et de 
vraies questions politiques, qui dépassent très largement les seules et classiques questions ségrégationnistes héritées des politiques coloniales.

7 Voici donc un excellent ouvrage, qui met en perspective de façon efficace la question de la criminalité urbaine en milieu africain. L'analyse de cette criminalité fort diverse requiert des approches locales, que J. Assiago appelle de ses vœux en conclusion. À l'échelle de l'Afrique de l'Ouest, il faudrait donc conduire d'autres études, notamment hors du Nigeria. La limite de ce recueil est d'être largement focalisé sur le géant nigérian, mais c'est aussi son mérite, vu l'importance des questions criminelles et sécuritaires au Nigeria, d'ailleurs peu analysé en tant que base arrière de réseaux criminels urbains dépassant ses frontières. D'évidence, la qualité des résultats publiés ici par un collectif d'auteurs français et africains devrait être une incitation au lancement de travaux similaires dans les autres pays de la région, notamment dans les pays francophones.

\section{AUTEURS}

\section{JEAN-FABIEN STECK}

Université de Paris 10-Nanterre -laboratoire « Géotropiques » 